\title{
MENINGKATKAN KESADARAN SISWA AKAN PENTINGNYA MENABUNG SEJAK DINI PADA SISWA SDN 01 SAWAH BARU CIPUTAT
}

\author{
${ }^{1 *}$ Pusporini Palupi J, ${ }^{2}$ Elizabeth Tika Kristina Hartuti, ${ }^{3}$ Yeni Septiani , \\ ${ }^{4}$ Ana Septia Rahman, ${ }^{5}$ Iriana Kusuma Dewi \\ Universitas Pamulang \\ Email : ${ }^{1}$ pusporini.palupi09@gmail.com
}

Manuskrip: Nov -2020; Ditinjau: Des -2020; Diterima: Des -2020;

Online: Jan-2021; Diterbitkan: Jan-2021

\begin{abstract}
ABSTRAK
Tujuan dari Kegiatan Pengabdian Kepada Masyarakat adalah untuk melaksanakan salah satu Tri Darma Perguruan Tinggi. Selain itu diharapkan dengan pengabdian kepada amsyarakat tersebut keberadaan perguruan tinggi dapat memberikan kontribusi kepada pengembangan penerapan keilmuan kepada masyarakat. Metode yang digunakan pada pengabdian kepada masyarakat ini penyampaikan materi secara verbal alam pelaksanaan ini materi dalam penyuluhan eduaksi disini mencakup anak diajarkan sejak dini untuk mengatur keuangan, anak diajakrkan skala prioritas mana yang penting dan tidak penting anak diajarkan untuk lebih menghargai uang, anak diajakrkan sifat mandiri dan konsisten untuk dapat mencapai suatu keinginan.

Hasil pengabdian masyarakat yang diperoleh adalah Menabung bisa mengajarkan anak untuk hidup hemat, karena mereka harus menyisihkan sebagian uang untuk ditabung. Hal ini akan membuat ank belajar dalam mengelola uang atau membeli mainan. Anak juga belajar bahwa uang mereka terbatas karena sebagian harus ditabung,

Ilmu yang diperoleh pada pengabdian masyarakat ini harapannya mampu memberikan pengetian sejak dini kepada siswa siswi SD sawah baru dalam upaya menabung dan mereka menjadi lebih menghargai uang. Kegiatan menabung yang terus berlanjut juga dapat menjadi kebiasaan pada anak sampai mereka dewasa.
\end{abstract}

\section{Kata Kunci : Menabung Sejak Dini.}

\section{PENDAHULUAN}

Dalam program untuk mensosialisasikan Semua orang dengan berbagai usia dapat melakukan kegiatan ini, termasuk juga anak-anak, Anak bisa menabung dari uang saku dan menyimpannya dalam celengan, menabung memiliki banyak sekali manfaat sehingga sangat penting untuk berlatih menabung sejak dini , anak - anak tentang kesadaran dalam menabung sejak dini. Menabung bisa mengajarkan anak untuk hidup hemat, karena mereka harus menyisihkan sebagian uang untuk ditabung. Hal ini akan membuat anak belajar dalam mengelola uang atau membeli mainan. Anak juga belajar bahwa uang mereka terbatas karena sebagian harus 
ditabung, maka anak akan lebih berhati hati dalam menggunakan uang dan mereka menjadi lebih menghargai uang. Kegiatan menabung yang terus berlanjut juga dapat menjadi kebiasaan pada ank sampai mereka dewasa. Dengan adanya edukasi tentang pentingnya menabung sejak dini guna untung memahami dan membiasakan mengelola uang saku mereka dengan baik dan tidak menjadi boros.

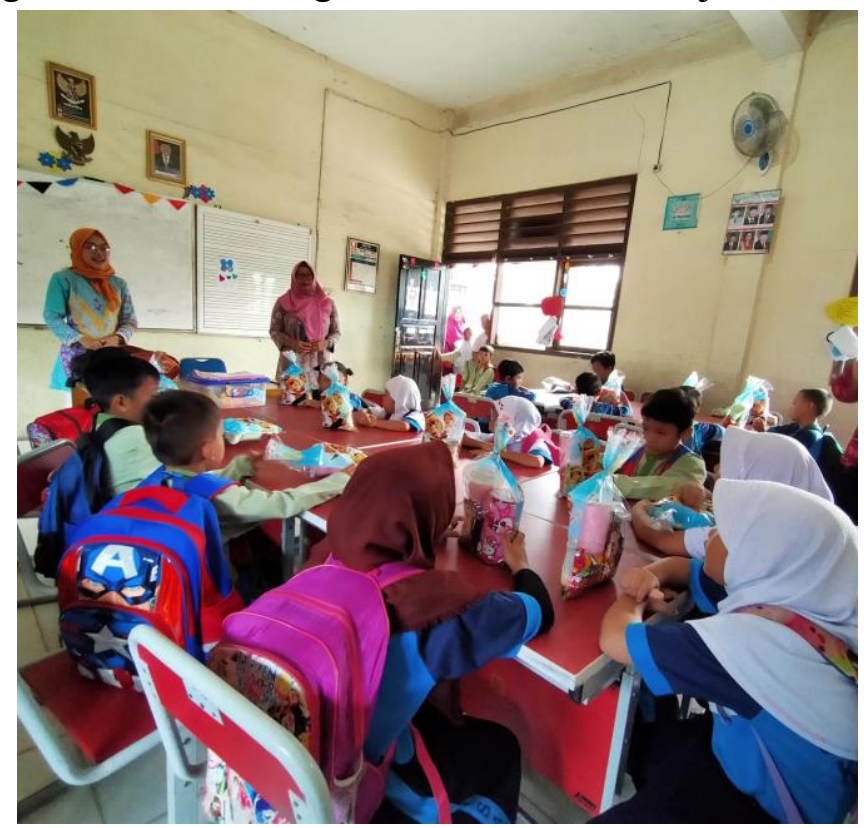

\section{Gambar 1. Kegiatan PKM}

Berdasarkan latar belakang masalah di atas, maka fokus pengabdian masyarakat dibatasi pada ruang lingkup meningkatkan kesadaran siswa akan pentingnya menabung sejak dini. Adapun kegiatannya adalah dengan memberikan edukasi secara visual kepada siswa siswi bahwa menabung memliki manfaat yang banyak dengan dilakukan budaya menyisihkan uang atau menabung.

\section{METODE PELAKSANAAN KEGIATAN}

Pembelajaran ilmu yang menjadi tema dalam pengabdian masyarakat ini yakni kegiatan yang bertujuan memperkenalkan sejak dini dalam budaya menabung sejak dini, yang dilaksanakan melalui pemberian materi, tanya jawab, pemberian media untuk menabung anak-anak (celengan).

Pengabdian kepada masyarakat ini dilakukan pada hari Jumat 29 November 2019, adapun tempat, waktu dan peserta pelaksanaan adalah sebagai berikut: Tempat di SDN 01 Sawah Baru Ciputat dan Waktu pelaksanaan yaitu pukul 09.00 - 11.30 WIB. Sedangkan Peserta sebanyak 35 Orang (Siswa kelas 1 dan dosen).

\section{HASIL DAN PEMBAHASAN}

Hasil pelaksanaan PKM yang dilakukan pada hari kamis, 29 November 2019 dengan peserta adalah siswa dan siswi SDN 01 Sawah Baru Ciputat bahwa : 
1. Kegiatan yang dilaksanakan untuk siswa dan siswi SDN 01 Sawah Baru adalah kegiatan untuk membiasan pada siswa sejak dini untuk memahami dan membiasan diri dalam mengelola uang saku mereka dengan baik dan tidak boros.

2. Para siswa dan siswi sengat merasa senang dengan materi yang mereka dapat dari dosen dosen manejemn Universitas Pamulang mengenai penerapan menabung sejak dini dan sangat memotivasi mereka dalam menabung sejak dini dalam menyisihkan sebagian uang sakunya.

3. Dengan keterbatas waktu yang ada para siswa dan siswi bisa mendapatkan celengan guna diterapkan dalam keseharian dalam menyisihkan sebgaian dari uang saku.

Respon dari para guru dan para siswa/siswi SDN 01 Sawah Baru sangat baik mereka sangat terbantu dengan adanya PKM dari para Dosen Manajemen Universitas Pamulang, menambah pengetahuan dan memotivasi para siswa dalam menabung dan sangat membantu nantinya dalam kebiasaan hidup sampai nanti agar terbiasa menabung dan gambaran seberapa penting dalam menabung serta pemahaman merencanakan keuangan sejak dini.
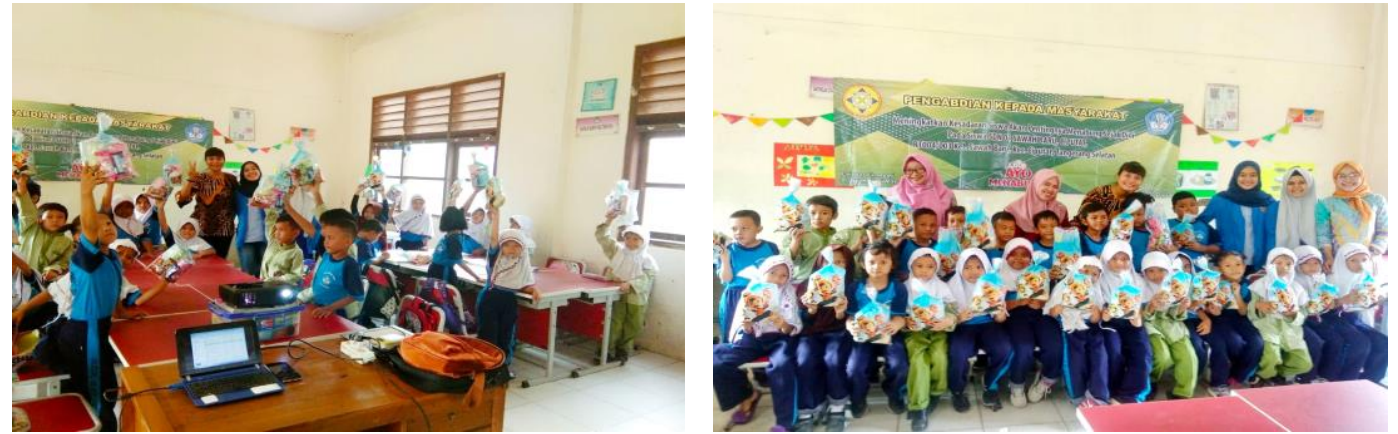

Gambar 2. Foto Bersama Anggota dan Peserta

\section{KESIMPULAN DAN SARAN}

Hasil kegiatan ini adalah Menabung sejak usia dini memberi manfaat yang positif pada anak. Baik untuk hari ini maupun di kemudian hari., mengajarkan anak menabung sejak usia dini bermanfaat untuk pembentukan karakternya. Secara luas, masyarakat dunia berubah dengan cepat dan dinamis, karena itu kita butuh sumber daya yang berkompeten. Dengan menabung, berarti kita memfasilitasi perkembangan seluruh aspek kecerdasan anak. "Saat menabung, anak mulai mengenal angka, belajar menahan diri, dan memahami mana yang jadi prioritas". Banyak yang beranggapan tidak baik untuk mengenalkan uang pada anak, karena anak dikhawatirkan akan menjadi konsumtif atau mata duitan, mengenalkan anak sejak dini pada uang justru mengajak mereka menghargai uang. Selain itu mereka juga sekaligus belajar berhitung dari nominalnya. Cara mudah mengajarkan anak untuk menabung, adalah dengan memberi mereka target dan perbandingan. Misalkan ingin membeli sesuatu atau mainan, maka mereka menabung dalam jangka waktu tertentu.

DisarankanPelaksanaan Kegiatan PKM ini diharapkan tetap dilakukan secara rutin di setiap kelas. Dalam menabug tidak akan merugikan para siswa siswi , kegitan 
tersebut dalam menabung sejak dini guna bermanfaat membetuk karakter siswa siswi sebagai orang hemat dan memenuhi kebutuhan. Terutama kebutuhan primary bukan apa ayng diinginkan.

\section{DAFTAR PUSTAKA}

Abdullah, M. (2011), Analisis minat menabung kota medan. Jurnal ekonomi dan keuangan.

Aisyah. (2013). Pengaruh Kualitas Pelayanan terhadap Minat Nasabah untuk Menabung (Studi Kasus pada PT. Bank Mega Syari'ah Cabang Semarang). Institut Agama Islam Negeri Walisongo, 12-13.

Akbar, Irfan Rizka,. (2018) Analisis Kebijakan Kepala Sekolah Dalam Upaya Meningkatkan Kompetensi Guru (Study Kasus Pada SMK Muhammadiyah Parung). Masters thesis, Universitas Pamulang

Bari'ah, dkk,Hubungan antara Kualitas Layanan Bank dengan Minat Menabung Nasabah PTBRI Kantor Cabang Ungaran,Semarang,Universitas Diponegoro.

Kasmad, K., Mustakim, M., \& Sunarsi, D. (2020). Increasing Community School Interest Through Service Quality, Prices and Promotion in Vocational High Schools. Journal of Educational Science and Technology (EST), 6(2).

Khoiri, A., Kusumawati, I., Kahar, M. S., \& Mursidi, A. (2019, February). Analysis of three representations in problem solving on additional relativistic velocities. In Journal of Physics: Conference Series (Vol. 1153, No. 1, p. 012136). IOP Publishing.

Lamb, Hair dan Mc Daniel., 2001. Pemasaran, Penerjemah David Octarevia, Buku, Jakarta : Salemba Empat.

Muara, Dayah ( 2015, Agustus) menabung sejak dini. http://unsyiah.ac.id

Notoatmojo. (2012), promosi dan perilaku. Jakarta: Rieneka cipta.

Rabbani,Sofa,AnalisisPemahamanNasabahterhadapKesyariahanBank BNISyariah,Yogyakarta:TesisProgramPascaSarjana Pada PascaSarjana Universitas Gajah Mada.

Sholahuddin, M., dan Lukman Hakim 2018, Lembaga Ekonomi dan Keuangan Syariah, edisi jilid 1, Surakarta, Islamic Banking.

Slameto,2010,BelajardanFaktor-FaktorYangMempengaruhi.Jakarta:

PT.RinekaCipta.

Trisnayanti, Y., Khoiri, A., Miterianifa, \& Ayu, H. D. (2019, December). Development of Torrance test creativity thinking (TTCT) instrument in science learning. In AIP Conference Proceedings (Vol. 2194, No. 1, p. 020129). AIP Publishing LLC.

Y Kadarusman, D Sunarsi. (2020). Pengaruh Strategi Penetapan Harga Terhadap Peningkatan Jumlah Siswa Pada SMK PGRI Balaraja. JS (Jurnal Sekolah) 4 (3), 213-221 